\title{
DESAIN SEBAGAI PRODUK DAN PRAKTIK DAN RELASINYA DENGAN ME- DIA DALAM INDONESIA 4.0
}

\author{
Adi Surahman \\ Desain Komunikasi Visual, Universitas Pasundan Bandung \\ e-mail: adisurahman@gmail.com
}

\begin{abstract}
ABSTRAK
Komunikasi sebagai sebuah proses penyampaian pesan dari komunikator (penyampai pesan) pada komunikan (penerima pesan) untuk mencapai kesamaan makna merupakan salah satu kebutuhan manusia sebagai makhluk sosial yang pada hakikatnya memerlukan berinteraksi antara satu dengan yang lainnya. Dalam proses komunikasi, interaksi ini dapat terjadi pada beragam tatanan. Beragam tatanan komunikasi sebagai bentuk interaksi manusia terdiri dari intrapersonal, interpersonal, kelompok kecil (small group), komunikasi publik, dan komunikasi massa. Klasifikasi tatanan komunikasi tersebut dilakukan berdasar pada jumlah orang yang terlibat dalam proses komunikasi; yang menempatkan komunikasi massa menjadi tatanan komunikasi yang melibatkan banyak orang, tersebar dan memiliki tingkat diferensiasi yang tinggi. Dalam komunikasi massa, secara konvensional, media yang lazim digunakan terklasifikasi dalam media cetak (surat kabar dan majalah) dan media elektronik (radio dan televisi). Artikel ini akan membahas kajian pustaka menggunakan Analisis Dokumentasi untuk mengidentifikasi potensi pengembangan Desain sebagai produk dan praktik dan relasinya dengan media di era Indonesia 4.0. Dalam hal ini, pendidikan tinggi desain berperan sebagai saluran pengayaan wawasan bagi mahasiswa untuk dapat memahami konsep yang kuat dan integratif dalam kaitannya menghadapi tuntutan kebutuhan Desain di Revolusi Industri 4.0.
\end{abstract}

Kata kunci: Produk Desain, Praktik Desain, Media dalam Desain, Indonesia 4.0

\begin{abstract}
Communication as a process of delivering messages from the communicator (messenger) to the communicant (the recipient of the message) to achieve the same meaning is one of human needs as a social being which essentially requires interacting with one another. In the process of communication, this interaction can occur in a variety of settings. Various communication arrangements as a form of human interaction consist of intrapersonal, interpersonal, small groups (small groups), public communication, and mass communication. The classification of the communication order is carried out based on the number of people involved in the communication process; which puts mass communication into a communication system that involves many people, spreads and has a high degree of differentiation. In mass communication, conventionally, media commonly used are classified in print media (newspapers and magazines) and electronic media (radio and television). This article will discuss literature review using Documentation Analysis to identify potential development of Design as a product and practice and its relationship with the media in the Indonesian era 4.0. In this case, design higher education plays a role as an insight enrichment channel for students to be able to understand a strong and integrative concept in relation to the demands of design in the Industrial Revolution 4.0.
\end{abstract}

Keyword: Product Design, Design Practices, Media in Design, Indonesia 4.0 


\section{PENDAHULUAN}

Media; medium; atau dalam bahasa Latin medius memiliki pengertian 'di tengah-tengah' atau 'udara', 'di antara'. Menurut Fiske, media merupakan bentuk jamak dari kata medium yang pada dasarnya adalah sarana teknis atau fisik untuk merubah pesan menjadi sinyal yang dapat ditransmisikan melalui saluran tersebut (Fiske, 1990). Secara fisik, media merupakan cara bagaimana suatu sistem tanda perekam gagasan bisa diaktualisasikan; sedangka media massa yang merupakan pembentukan atas dua kata yaitu 'mass' dan 'media' dari asal katanya mengandung pengertian mass yang mengacu pada penerimaan media secara besar-besaran (massive) seperti televisi, film dan sebagainya (Laughey, 2007).

Dalam berkomunikasi, manusia mungkin saja tidak menggunakan media massa, namun bisa juga menggunakan suara, kata, isyarat sebagai medium dalam penyampaian pesan. Ada tiga penemuan yang berkaitan dengan komunikasi sehingga tatanan berubah, penemuan tersebut adalah alfabet fonetik, mesin cetak, dan telegraf. Setiap media mempunyai struktur metode khas dalam berkomunikasi misalnya lisan, tertulis, cetak, elekronik, dimana media yan berbeda membangkitkan pola di otak secara khas pula (McLuhan, 1964).

\section{Pembahasan Teori}

Budaya lisan, atau bahasa tutur, merupakan sistem tanda pertama yang memungkinkan antar manusia berkomunikasi dan melakukan interaksi. Sistem tanda yang kemudian muncul sebagai awal mula bahasa tulis adalah piktograf, seperti yang digunakan oleh Bangsa Sumeria di 3500 SM dan hieroglif Mesir sekitar tahun 3000 SM .

Penggunaan piktografik kemudian mengembangkan sistem simbol abstrak yang disebut huruf atau karakter, bentuk imaji konkrit yang mengobjektivikasi benda atau gagasan. Sistem tanda ini tidak mewakili seluruh konsep, melainkan men- jadi bunyi-bunyi yang menyusun kata-kata, disebut sebagai sistem alfabet. Alfabet menjadi sebuah terobosan yang memungkinkan dilakukannya pengawetan peristiwa dalam bentuk teks yang tersusun menjadi buku. Penemuan sistem tanda alfabet juga menandai lahirnya masyarakat melek huruf.

Perubahan yang sangat signifikan kemudian terjadi pada abad ke 15 ketika munculnya teknologi kertas dan mesin cetak Johann Guttenberg yang memungkinkan cetak buku bisa dibuat dengan cepat dan semakin murah. Melalui artefak cetak (buku, surat kabar, selebaran dan sebagainya), setelah abad ke 15 kata-kata yang tertulis menjadi cara yang utama dalam menyimpan dan meneruskan pengetahuan dan gagasan. Sejarah media terus berlanjut sampai pada akhirnya ditemukannya fonografi pada tahun 1877 oleh Thomas Edison, radiotelegraf (kemudian disingkat dengan radio) yang ditemukan oleh seorang insinyur Amerika bernama Guglielmo Marconi pada tahun 1895, dilanjutkan pada tahun 1877 dengan ditemukannya sistem peralatan perekam citra bergerak atau film. Perkembangan media selanjutnya ditandai oleh Paul Nipkow sebagai orang yang pertama kali menemukan televisi yang mengalami perkembangan sejak tahun 1923 sampai 1925, hingga sekarang.

\section{Uraian Permasalahan}

Perkembangan desain terkait erat dan secara selaras berkembang sesuai dengan sejarah perkembangan media yang secara singkat telah dipaparkan pada bagian sebelumnya. Ketika pada tahap dasar komunikasi primer adalah proses yang terjadi tanpa perantara antara penyampai pesan dengan penerima pesan terjadi interaksi secara langsung menggunakan bahasa sebagai lambang dan tidak diperantarai media; desain belumlah memiliki fungsi dan pengaruh baik secara produk dan/atau praktik. Terobosan teknologi media yang terjadi memulai pula era perubahan bentuk serta 
Vol. 6, No. 1, Oktober 2018

perwajahan media, yang kemudian berdampak memunculkan perubahan pada desain.

Guttenberg dengan terobosannya memungkinkan desain untuk "membendakan" pikiran dan gagasan, memproduksi massal beragam representasi dari beragam kisah dan beragam simbol yang selama ini hanya ditansmisikan secara turun-temurun melalui budaya tutur. Ditemukannya sistem tanda alfabet memungkinkan manusia untuk memanfaatkan kemelekhurufan dan mengimplementasikan sistem tanda tersebut menjadi serangkaian desain informasi di media cetak sehingga dapat tersebar secara luas dan melahirkan perkembangan metabudaya yang berpengaruh kuat pada perkembangan tingkat kognisi manusia.

Kemungkinan desain informasi melalui media cetak termasuk juga menyebabkan terjadinya perubahan pikir sekaligus perilaku manusia, seperti yang diungkapkan dalam sebuah studi tentang media bahwa 70 persen pembaca surat kabar menyetujui pernyataan yang berisi "The paper helps me to decide where to shop and buy" dan 65 persen pembaca merasa bahwa surat kabar jauh lebih penting dari televisi dalam menentukan perilaku konsumen (Katz, 2003).

Relasi desain dan media kemudian berkembang semakin pesat saat studi mengenai bidang ilmu tipografi mulai menjadi kajian yang khusus. Hieroglif berupa gambar-gambar sebagai representasi bentuk bahasa verbal dan aksara yang menjadi dasar pengembangan tipografi menjadi sebuah lompatan ilmu dalam desain yang diterapkan menjadi pengembangan pada sistem tanda alfabet. Pada situasi relasional ini, tipografi dalam desain informasi menempatkan desain sebagai praktis, digunakan secara berulang dan membangun sistem tandanya sendiri.

Jika mesin cetak Guttenberg dan sistem tanda alfabet memberikan terobosan pada produk desain dalam pengawetan gagasan dan membedakan pikiran manusia dalam wujud reproduksi tulisan, penemuan radiograf sebagai media audio pun turut memberikan pengaruh terhadap relasi desain dan media. Radiograf yang memungkinkan untuk membendakan pikiran manusia ke dalam wujud reproduksi suara, mengubah bentuk reproduksi kata dan bahasa dari tertulis dan tercetak (stimuli exposure bagi indra visual) menjadi terekam (stimuli exposure bagi indra pendengaran).

Dalam budaya massa yang terbentuk sebagai bagian dari proses industrialisasi, media menjadi saluran industrialisasi pikiran. Desain berkembang sebagai 'artikulasi' yang membantu membentuk pikiran secara massal. Melalui teknologi perekam citra yang menghasilkan produk sinematik film menggunakan suara dan gambar, desain memiliki daya untuk menampilkan ulang sesuatu yang dicerap, di indra, dibayangkan atau dirasakan secara fisik. Media menghadirkan realitas di dalam wujud representasi, desain pada posisinya sebagai praktik pun mulai memperkenalkan produk visual kepada masyarakat. Jika sebelumnya fotografi dianggap cukup meng-antara-i imaji dan ingatan seseorang atas kejadian, benda-benda, objek-objek pada suatu peristiwa, kesemuanya berubah menjadi petanda dan penanda dalam film. Film menciptakan reproduksi, rekonstruksi, representasi realitas menjadi realitas media. Tidak hanya film, televisi sebagai produk artefak merupakan karya desain yang dicirikan oleh keragaman jenis, bentuk, merk. Televisi mendesain susunan peristiwa yang berulang, yang hal ini menurut Ricoeur (1983), televisi melakukan narasi, yaitu aktivitas manusia yang diartikulasikan melalui tanda - tanda, hukum dan norma (Ricoeur, 1983).

Integratif dan Kolaboratif sebagai salah satu karakteristik pembelajaran pendidikan tinggi seperti yang tertuang dalam Permenristekdikti No. 44 Tahun 2015 Pasal 11 memberikan ruang bagi pendidikan tinggi Desain melakukan pengkajian dan pengembangan media ke arah praktik yang lebih multidiplin. Lambat laun, Desain tak hanya membendakan pikiran manusia, na- 
mun juga memberikan pengaruh dalam proses internalisasi nilai dalam diri manusia. Selain menghasilkan artefak, desain melahirkan gaya hidup dalam ruang sosial dan memengaruhi terjadinya praktik sosial. Desain menghasilkan tanda-tanda sebagai tiruan tak sempurna dari realitas. Desain menciptakan inovasi relasi dengan media dalam penciptaan model-model, simulasi, pencitraan. Desain mewujud menjadi produk sekaligus praktik. Penemuan teknologi komputer menyebabkan terjadinya terobosan lain dalam kajian relasi desain dan media. Melalui teknologi komputer, desain sanggup mengubah tingkat interaksi manusia dan intensitasnya dalam pemanfaatan teknologi dari keberagaman menjadi keseragaman.

Pencitraan melalui desain yang dikembangkan dengan teknologi komputer melahirkan tanda - tanda baru, makna-makna ganda atas realitas, ruang kemungkinan yang mengantarkan pencitraan hidup melalui dunia hiper-realitas. Situasi demikian, ketika budaya massa semakin melunturkan filosofi dan acuan moral bersama dalam masyarakat massa, justru dianggap sebagai puncak relasi antara media dengan manusia. Di dalam puncak relasi tersebut, desain, media dan tindak komunikasi menjadi sebuah proses kreativitas dan evolusi biologis dalam (dan) budaya. Desain menjadi 'ekspresi' yang bukan hanya persoalan 'fungsi', namun juga 'bahasa' yang digunakan untuk mengartikulasikan 'sesuatu' (pesan).

\section{Kesimpulan}

Relasi antara desain dan media terjadi selaras dan/atau mewujud sebagai dampak dari sejarah perkembangan media. Dalam relasi ini, komunikasi menjadi proses yang melibatkan tanda-tanda dan kode-kode (all communications involves signs and codes) yang disistematisasikan dan direpresentasikan melalui desain menjadi sistem tanda yang kemudian dikirimkan (ditransmisikan) melalui perangkat teknologi (media) dalam masyarakat massa yang (kemudian lebih jauhnya) melahirkan budaya massa. Dari paparan tersebut dapat disimpulkan bahwa di era Indonesia 4.0, Pendidikan Tinggi Desain memiliki peranan yang signifikan dalam studi media dan eksplorasi wujud media, terkait konteks Desain sebagai 'entitas komunikasi' yang di dalamnya terkandung beragam gagasan, dalam hal ini, baik posisi Desain ditempatkan dalam artian praktik maupun produk. 
Fiske, J. (1990). Cultural and Communication Studies: Sebuah Pengantar Paling Komprehensif. Yogyakarta: Jalasutra.

Katz, H. (2003). The Media Handbook: A Complete Guide To Advertising, Media Selection, Planning, Research, and Buying, Second Edition. London: Lawrence Erlbaum Associates Publishers.

Laughey, D. (2007). Key Themes in Media Theory. New York: Open University Press. McLuhan, M. (1964). Understanding Media. New York: Gingko Press Inc. .

Ricoeur, P. (1983). Time and Narrative, vol. 1, translate K. Mclaughlin and D. Pellauer. Chicago: University of Chicago Press.

Uchjana, O. (2000). Ilmu, Teori dan Filsafat Komunikasi. Bandung: Citra Aditya Bakti. 